Kohl: a Journal for Body and Gender Research

Vol. 5, No. 2 (Summer 2019)

\title{
Medical Patriarchy: The Case of Legal Midwives in Lebanon
}

\author{
Hiba Abbani
}

Translated by Hanine El Mir

\begin{abstract}
:
The economic status of women today is neither a mere coincidence, nor a result of their ability (or lack thereof) to take on other jobs; it has nothing to do with their "nature," despite the legends propagated on their behalf, starting with the creation myth. The existence of Eve was a sufficient motive to fight her, an approach that persists to this day, albeit using different tools and weapons, and that is engrained in our very structures. These violent battles have been bloody, despotic, or both, but they all served to transform myths into beliefs or general rules that inform how women are perceived. Not always visible or evident, these myths can have malicious consequences, especially when they claim that women lack the capacity, merit, eligibility, and credibility to reach certain positions in the social and economic ladder. As a result, women are left at the bottom of the ladder in terms of professional status, wages, working conditions, and, most importantly, the value attributed to their work. Throughout this essay, I seek to contribute to refuting the myths about women at work, especially those involved in the healthcare fields. To do so, I shed light on the work of legal midwives (kabila), and traditional midwives (daya), and the fundamental role they play in the health of women and mothers. I also aim to highlight some historical and contemporary facts to address the historical erasure of women's achievements, and to contribute to bringing justice to midwives in the face of the ongoing distortion, prejudice, and isolation under the current health system.
\end{abstract}


Midwifery is considered one of the oldest professions in history. Intrinsically associated with the women who have practiced it for centuries, its accumulated knowledge and experience is passed from mother to daughter up until today. These women were referred to as qabila and daya, feminine terms that, linguistically, have no masculine equivalent in Arabic. Midwives were a safety valve that supported pregnant women and the communities they belonged to, assuming the role of counseling partners. Yet, having completely excluded women from the medical sector through violence, intimidation, and defamation, the patriarchal and capitalist system dispossessed midwives of their social status and health sphere, especially maternal health. As a result, pregnant women no longer received their care and support from midwives; instead, this relationship was replaced with medical specialization in general, and what is now known as obstetrics in particular. This led to men/doctors replacing women/midwives in women's most intimate and intricate moments, those of pregnancy and childbirth.

Because of my commitment to bringing justice to midwives, I adopted a methodology that relied primarily on conducting interviews with them; in other words, they are the primary source of this essay. I conducted five interviews with five midwives from different regions and contexts: two of them work in a hospital, one in her own private clinic, a fourth, the founder of the Lebanese Order of Midwives, teaches at the Saint Joseph University (USJ), and the last one works in the Order. However, all of them have worked at a hospital at some point. In addition to the field work, I reviewed literature on the history of medicine, women, and midwifery, as well as statistics and data related to reproductive health, maternal health, and global indicators. I also looked at global literature and studies with the aim of positioning my research in histories and politics that contextualize the evolution of women's work in healthcare and how our perceptions and understanding of health and women changed as a result of global processes, namely colonialism. As for the Lebanese context, I found it difficult to find an abundance of texts that chronicle the work of legal midwives and provide a complete picture of women's transition from traditional to legal midwifery, and eventually to midwives helping obstetricians. In addition to the interviews and resources providing insights into the history of the emergence and development of medicine in Lebanon, I base my study in oral histories told by women.

The paper first sheds light on the global and local (Lebanese) historical context, to showcase the discursive distortions of women's work in the health sector. This section acts as a temporal bridge that I go back to in several instances of the paper. I then turn to the legal and material situation of legal midwives, analyzing the gaps and shortcomings of the medical model under which maternal and obstetric health fall. I compare the obstetrics-dominated field with that of midwifery, based on midwives' testimonies, and in different contexts, based on existing research.

\section{The Historical Background}

The pain I felt when I was seven years old did not subside until my grandmother rubbed some hot, aromatic oil on my stomach. Her hands were simultaneously gentle and firm. My grandmother could not differentiate the letters of the alphabet, and only learned of how school worked through my daily absences. But she had inherited her mother's knowledge - that of Mother Nature. She knew of the secrets of the rough land between two mountains, and the treasures that take root there. Women had the gift of healing for hundreds of years before its knowledge reached my grandmother, perhaps because they were the closest to nature and the earth's offerings. 
Before the advent of modern science, women's science was the nature that surrounded or intrigued them. Some of the cures and treatments they discovered are still used today:

The wise woman, or witch, had a host of remedies which had been tested in years of use. Many of the herbal remedies developed by witches still have their place in modern pharmacology. They had pain-killers, digestive aids and anti-inflammatory agents. (Ehrenreich, 1973, p.14)

Women were pioneers in medicine and healing, although they did not have the financial resources, freedom of movement, and funds to develop their practice. Instead, they were punished for it. From the 14th to the 17thcentury, Europe's witch hunts targeted women, especially healers, through campaigns organized by the church and the state. In the late 15th and early 16th centuries, thousands of executions were carried out. The number of executions is estimated to average 600 per year in certain German cities, or two cases per day; 900 witches were executed in a single year in Würzburg, and 1000 in Como and its vicinity; in Toulouse, 400 people were executed in one day; in the Roman Catholic Diocese of Trier, the total number of deaths is estimated to be millions (Ehrenreich, 1973, pp.7-8). In the U.S., healers were isolated through specialization trends: they were legally prevented from practicing in favor of expensive and inaccessible "specialized" services.

The barbaric and exclusionary practices coincided with campaigns of defamation, distortions, and satanic accusations directed at healers, who were prevented from moving forward alongside the evolution of medicine. As a result, their vision of community service and natural resources was replaced by a practice that favored market standards, supply, demand, profit, and capital accumulation over the human. Witches, Midwives and Nurses: A History of Women Healers recounts the history of women in the health field: "Witch-healers were often the only general medical practitioners for a people who had no doctors and no hospitals and who were bitterly afflicted with poverty and disease" (Ehrenreich, 1973, p.13). The fierce war resulted in healers becoming nurses and assistants to male doctors with university degrees, who had exclusive access to the resources of the modern medical institution. Rather than stemming from the desire to improve people's health, modern medicine came as a result of the violent political and financial crackdown in Europe, and capital injections and lawlessness in the U.S. What we know about women's contributions to the health sector and their communities are brushed over; only their failures are mentioned. In contrast, huge medical institutions with ample financial, human, and political resources do not seem to be fulfilling their role of improving healthcare: services are either unavailable or inaccessible due to their exorbitant costs, and the results are not in line with the hopes and expectations of modern medicine. The $2018 \mathrm{WHO}$ health monitoring report highlights multiple worrying results. According to statistics, 303,000 women died of maternal causes in 2015, most of whom were from low to middle income countries (WHO, 2018). In 2017, 151 million children under the age of five suffered from stunted growth, 51 million of them were underweight, and a high proportion of young people were at risk of heart attack (Ibid.). 41 deaths out of 57 million (71\%) resulted from non-communicable diseases (Ibid.). Widespread medical errors and failures continue to occur: despite verbal complaints, the medical institution is legally, politically, and socially condoned and given votes of confidence by still being sought as the only credible reference for all health-related matters. Midwives were prevented from practicing their profession for long periods; they saw their value decrease and their role in the maternal health sector restricted to that of a nurse. In other words, they became an auxiliary for the male obstetrician, who is 
confident in his competence, as his role is a preferential one when it comes to women's care in their most intimate moments.

The repressive and bloody history left an imprint on Lebanon, a country born out of colonialism, fully implicated in European systems and curricula, and inspired by contemporary slogans of market liberalism. When it comes to midwives, the medical landscape began to change as American and missionary doctors arrived to Lebanon. With the enforcement of new laws, the practice of medicine established itself and old practitioners were referred to as sorcerers. American evangelical missionaries, who had close ties to Europeans, introduced higher education in Lebanon and founded the American University of Beirut (AUB). Similarly, the historical, legal, and social development of the health field is almost identical to American and European models, as it went through gradual institutionalization and repression of "non-specialized" medical practitioners. Foreign doctors introduced new concepts to the established standards and conditions of medical practice. According to Samir Kassir in The History of Beirut, "until the middle of the nineteenth century, medicine in Beirut was practiced in an improvised manner... but things went in a different direction with the Egyptian reforms and the growth of trade in Europe. In 1839, Blondel pointed to the existence of a pharmacy managed by a specialized pharmacist, explaining that the shops of other 'Attars' (herbal healers) do not meet the required conditions" (Kassir, 2006, p.243). Medical specialization thus gained legal, social, and cultural ground, placing the doctor in a prestigious position where "people regard him as a demi-god" (Kassir, 2006, p.244).

The scientific or specialization trend has evolved due to the spread of schools and the emergence of the first two universities in Lebanon: the Syrian Protestant College (now known as AUB) and the Saint Joseph University (USJ), as American and French missionaries played a decisive role in bringing higher education to Lebanon. According to Massoud Daher, "the schools of Mount Lebanon in the 19th century were all in the hands of monks and missionaries... American missionaries were the first to introduce medical practice into educational work in Syria and Lebanon" (Daher, 1974, p.219). The two institutions were in constant competition as they represented the interests of colonialism in the East (Ibid.). This led to the decline of the Arab University in Damascus, as it became dependent on a (mostly) French, educational body (Daher, 1974, p.229-232). Similarly to the global context, higher education, especially medicine, was not available to the public, but was reserved for the privileged classes. Medical professional success required specialization and pursuing further studies in Europe to gain credibility. Samir Kassir notes that "doctor advertisements in Beirut showed the certificate's type, number, and, of course, the university from which it was issued" (Kassir, 2006, p.244-245). Parallel to institutionalizing and praising modern medicine, traditional practices were bashed in campaigns that described them as witchcraft, accompanied by legal prosecutions and the shutting down of illegal drug shops to help spread European medical methods fully (lbid.).

While we do not know much about the specific conditions of women under these transformations, their role was undoubtedly redefined in healthcare and medicine. Before the existence of legal midwives, we knew these practitioners in Lebanon and in the Arab region as dayas. Like their global counterparts, Arab dayas inherited their knowledge from their mothers and grandmothers. They accompanied pregnant women throughout childbirth and postpartum. It is regrettable that no documentation of their work and its importance is available, aside from oral history and online testimonies. The lack of documentation is consistent with the approach of exclusion and erasure of women from history. It also contributes to shifting 
the conversation around dayas towards their claimed inefficiency, deeming them responsible for the high rates of child and maternal mortality in addition to the complications of childbirth. It is known as well that midwives practiced this kind of work for many years and gained the trust of women and whole families, despite their limited equipment and resources. As stated by daya Um Muhammad in an online interview:

One beautiful memory, when a woman gave birth to triplets, the Hajja felt a great joy. The Hajja notes that the triplets are now over forty years old and continue to send their regards to her with their mother. In some other cases, other families visit and check up on her still, some even bring gifts with them as a way to express gratitude, love, and respect towards her. (Habib, 2001)

Clearly, it is not their clients who resent midwives; our mothers and aunts would probably praise the women who assisted their mothers during childbirth, and supported and encouraged them by providing them with a safe space with all the resources available to them. But the emergence of medicine and obstetrics as a specialization portrayed dayas and even legal midwives as backward and ignorant. My intention is not to deny the possible complications and malpractices that could arise, given the vast difference in resources, equipment, and access to information between midwives and doctors of modern medicine. However, the systematic erasure of midwives' efficiency and social impact amplifies pregnancy and childbirth problems, even when these are the result of wars, living conditions, malnutrition, and other factors. Many question marks exist about modern medical models and approaches to maternal health that I will later address.

In this context, Nayla Doughane, the founder of the Lebanese Order of Midwives, says:

Dayas have been assisting in childbirth for a very long time. But, doctors considered their work to be problematic, linking it to complications such as infections in children and maternal or fetal mortality, which is why they created a school for legal midwifery. In addition to that, the daya played a very important role in villages, where everyone would seek her out, especially seeing as their culture depended on health practitioners visiting patients at home, since people weren't used to going to hospitals for health services, but quite the opposite. While she was doing everything from obstetrics and childbirth to maternal health and care, the doctors thought they ought to benefit from the matter and invented the concept of nurses, which later became midwifenurses. (Doughane, 2019)

This led to the daya losing her social status and the trust she had gained over the years. Even when she would enroll in schools and get accredited, the daya would still come second to the obstetrician (most frequently a man) as he takes over women's health and childbirth. This change was not merely a handover of tasks from women to men, but a complete change of vision, from community work to institutionalized commodities, from comprehensive care to a number in the doctor's database.

As Nayla Doughane puts it:

Midwifery in Lebanon originated with the daya. The daya had the authority back then to appoint a mayor or remove him from the office... However, she is no longer regarded as such, and people are no longer aware of her practice's value or the role she plays. They worked all over the world when births were taking place at home. And doctors would take notes of the midwives' practices 
to learn from them, until they decided that this practice caused medical complications and erased it. Historically, childbirth was a collective act, involving parents and neighbors, while the midwife assisted the pregnant women at home. Those who did not have any family members would go give birth in a hospital. (Doughane, 2019)

\section{The Current Status of Legal Midwives in Lebanon 1) Legal Frameworks: Ethics First?}

Lebanon began imposing restrictions, conditions, and qualifications on dayas following their categorization as unqualified. While dayas may have needed to develop their skills and expand their knowledge, especially with the challenges that may arise with pregnancy, the imposed educational frameworks contributed to their exclusion. The new order relied on midwifery schools as the only mean to transfer knowledge. Moreover, schools were established in the capital, making it impossible for rural women to access them. Women's education was still predominantly considered unfavorable or unnecessary, as women's "primary role" was to take care of their homes, their families, and their children. Consequently, this centralization of educational institutions, coupled with the imposition of formal training as a prerequisite for practice, prevented a large number of women from engaging in this profession, making traditional midwifery illegal and socially unacceptable. While these restrictions did not stop women from practicing in villages and remote areas, they resulted in hierarchies between midwives. Dayas were uneducated and unrecognized by the law, while the legal midwives had pursued training and were certified. This laid the foundation for changing the prevailing culture, from one that depended on the daya to another that trusted the educational institution and the availability of its preventative methods at the expense of popular knowledge. This maternal health service remains available in remote and poor areas, where women and their families are unable to access modern medical services.

In this context, Nayla Doughane pointed out:

The first midwifery school in Lebanon was conceived in 1920. For women to become qualified to practice midwifery, they were required to have baccalaureate degrees to be eligible to attend university. This alienated many of them. It's also worth noting that they university was in Beirut, and women were neither allowed to leave their villages to live in the city, nor could they afford the tuition fees. Those who were able to attend university either stayed in Beirut to work after completing their studies or went back to their villages to practice for free because of how close everyone was to their neighbors in the village. Those who went back to the village didn't have a good return on their financial investment in university. (Doughane, 2019)

As time went by, the newly enforced conditions became more explicit and mandatory. They forced midwives to enroll in universities and obtain permits to practice the profession. It is interesting to note that before 2003 , midwives had to study nursing first so that they could then become legal midwives. This confirms the sentiment that women in the health sector only allowed one single place, that of nursing. Of course, this specialization was not available financially and geographically to many women, as no branch of the Lebanese University could provide it. It remained only in the grasp of the Saint Joseph University, 
which pioneered the establishment of the midwifery school in 1920, followed by a post-nursing college that finally molded into a major of its own in 2003.

Sonia Osman, a legal midwife from Tripoli, tells us about these educational restrictions:

Midwifery was not available in the Lebanese University in Tripoli. It was only available in the Saint Joseph University. Before requiring university degrees to practice midwifery, we had the Dalal Aseel Institute of Nursing that taught knitting and other "women-related" roles, including midwifery. Before the emergence of midwifery schools and specialized universities, I met midwives from all of Lebanon, like Sidon and Tyre, who attended the institute here in Tripoli. They couldn't afford to pay the expensive cost of the Saint Joseph University. However, the Institute no longer exists because the state announced that it is no longer legal to study midwifery at institutes, but only at university. (Osman, 2019)

In 1979, the Lebanese government issued a decree that regulated midwifery in accordance with mandatory conditions for its practice (Center for Research and Studies in Legal Informatics, 1979). These conditions included a certificate in midwifery from a university or school recognized by the Lebanese state, in addition to obtaining the baccalaureate and succeeding in the colloquium exam conducted by the Ministry of Culture and Higher Education for this purpose. Thus, midwifery turned towards specialization and became an institutionalized profession, subject to the standards of modern science introduced to Lebanon through colonial European education, especially French and later American. The first condition stipulates that "[the midwife] should have the health, mental, and moral qualities necessary for the practice of midwifery," while article 11 of the Penal Code states that "every convict sentenced to a felony or attempted felony or infidelity or misdemeanor or proven to have a mental disorder or addiction to alcohol or drugs is not entitled to practice the profession. They lose their permit should the Minister of Public Health decide so" (Center for Research and Studies in Legal Informatics, 1979).

Seeing that the Lebanese patriarchal state is highly predictable, its discrimination and devaluing of women is expected. Unsurprisingly, morality and mental integrity are absent from the decrees governing the work of pharmacists or doctors, and is only present in those that have to do with both midwifery and nursing. It would be naive to dismiss such observation as a coincidence, as opposed to an expression of a governmental effort to control and contain women in these professions, and consequently in the health field. If we assume the objectivity and necessity of the morality condition, why do we not find it in the decrees regulating the professions of pharmacy (Center for Research and Studies in Legal Informatics, 1950), or medicine (Doctors Without Borders, 1979), both in constant contact with patients (Center for Research and Studies in Legal Informatics, 1979)? This condition alludes to a hidden link between mental imbalance and women, as if women were "mad" by default, and everything else was an exception to the norm. This pattern is not unique to the Lebanese state or to modern times. The masculine myth has branded women as hysterical, mad witches. The burning of witches centuries ago was not only transformed into sophisticated texts that protect the modesty of the global system of rights and civilization, but they carry a scourge, which affects minds, souls, and daily bread to keep reproducing the patriarchal myth of women as "lacking in mind and faith." 
To that effect, the Lebanese state should define what morality is before imposing it as a first condition to practice midwifery or nursing. How can we know what moral qualities are and how they are measured and applied? Is it considered an immoral act when midwives and nurses have sex? Is hosting men at home an immoral act? Does arguing with a doctor in the hospital regarding a procedure make them unethical? Is allowing their coworker to take them home considered a doubtful act? Can they consume alcohol? Are their relationships with their husbands and children taken into consideration when measuring their level of obedience and compliance? And what about men - should they not have morals too?

None of this is surprising under a political system that derives its dominance from sectarian personal status laws that renounce all difference, as sectarianism is the most important unit for the reproduction of the system's rules, laws, institutions, tools, concepts, and ethics. Family is the basic component of society and the exclusive gateway to citizenship and access to rights. Thus, family ethics become a representation of those of the nation. And since the honor and morals of the family are radically linked to those of women, their oppression and "discipline" becomes a form of preserving the honor of the family and thus the homeland. It becomes a justification for the continuing systematic discrimination against women, keeping them under the tutelage of their male relatives. A woman goes from being a citizen with rights and duties to one who is under the guardianship of a man, bearing his name and safeguarding it within and outside the family. Therefore, such a system needs to control the behavior and practices of women in public areas so as not to contradict the ethical and hierarchical structures and the functional family unit, and to ensure its survival. The moral accountability of women in civil and penal laws is also distinct: the law distinguishes between the adulterer and the adulteress and penalizes women married to foreign men by depriving their children of their nationality, limiting their access to work, stripping them of sexual and reproductive decisions, and controlling their bodies.

Certainly, our perception of "ethics" differs from those of the state. It is also different from the word's inevitable positive echo, as this shiny terminology, "ethics," works in the same manner. No one dares to object to a system of ethics, lest they are willing to bear the weight of being branded as immoral and unethical. Thus, the Lebanese state appears to be concerned with public affairs and keen on preserving social safety in the face of the moral degeneration of women, which threatens our social structure and identity, guarded tirelessly by angelic male guardians. At the same time, women midwives and nurses become easy targets when it comes to morality threats, irrespective of the act's relevance to their profession. This increases their vulnerability to any injustices they face, such as medical disputes, competition for status, sexual harassment, violence, and other challenges.

On the other hand, this decree carries a dimension that the midwives regard as positive for determining their legal role and giving them powers that would grant them some independence. It states that:

Article (1) The legal midwife is authorized by the work of natural obstetrics, she ensures the health of the pregnant woman during the period of pregnancy and, when the situation occurs, performs all tasks related to her job.

Article (2) In case of obstruction of labor, the midwife must call the doctor or send the pregnant woman to the hospital.

Article (3) The midwife has the right to work alone, in the maternity ward, in obstetrics and gynecology departments, hospitals, dispensaries and in pediatric clinics within the limits of her professional duties. 
Article (4) The tools and medicines which the midwife has the right to use when practicing her profession shall be determined by the Ministry of Public Health. (Center for Research and Studies in Legal Informatics, 1979)

While some aspects of this decree appear to be promising, particularly in the first article, it maintains a form of hierarchy between the doctor and the midwife in the second article. It also does not specify which drugs are eligible to be prescribed. The midwives interviewed said that the list of these drugs keeps changing and getting tweaked to exclusively contain antibiotics. This leaves the midwifery practice subject to the mercy of the official decisions rooted in institutional bureaucracy, political strife, and masculinity. Adversely, the reality on the ground and in the field of application reflects a completely different picture.

\section{2) Midwifery in the Applied Space}

Once a widespread practice, home births are rare today. The choice of home deliveries was a haven for those who could not afford the cost of giving birth in a hospital. In Lebanon, the belief that the hospital is the safest place to give birth is still prevalent. Interestingly enough, the United States and the European countries that have created modern medical institutions are increasingly going back to home deliveries, as they provide the most comfortable and supportive environment for women in pregnancy and childbirth:

The demand for maternity homes is growing year after year. In Western European countries, more than $75 \%$ of births are attended by legal midwives. In the United States, a study by the National Assembly of America shows that demand for maternity homes is increasing massively. Accordingly, the birth rate increased from 20,000 in 1975 to 200,000 in 1994. (Al Hayat, 2014)

Home deliveries help midwives cut costs through not having to set up a clinic, as well. However, this radical change has put midwives in front of an equation that places professional independence and economic efficiency against each other. The right to professional independence becomes a luxury for those capable of incurring financial hardships or a painstaking effort that women repay in money, time, patience, and perseverance. Midwives are then only left with these choices: hospitals, private clinics, and more recently as a result of the Syrian crisis, the primary health care centers of the Ministry of Health and local and international civil society organizations.

Once again, practical reality dictates that midwives choose one and not the other. The available vacancies in health centers and organizations are newly established and are closely related to the Syrian crisis; it also puts them in another hierarchy. Despite the good effects this experience has had on the capacity of midwives and the tremendous response they have provided under the health system, Lebanon considers health a commodity meant for wealthy people alone, leaving the poor and those with limited incomes without health coverage. In this context, Margie Middleton, a legal midwife and project manager for maternal and female health care at Doctors Without Borders states that: "Not many refugees have connections in Lebanon, which makes it harder for them to find help within the local community" (Doctors Without Borders, 2013). She adds: "Pregnant women often do not know where to go. We have heard stories about women who have had to give birth alone, without help, and under a tent. I am very much touched by such stories because I am a midwife and I know how dangerous it is and the extent of the suffering and the horror a mother faces when giving birth alone" (Doctors Without Borders, 2013). 
The establishment of a private clinic is not an effective option either. The midwife who chooses to work in her private clinic faces many obstacles, most notably being regarded as inferior in the Lebanese mentality, including women who believe in the superior legitimacy of doctors. In the event that the midwife was able to pay the university fees first and then provide the necessary funds to establish the clinic, she would still have to allocate additional funds to prove herself to women who would choose coming to her clinic over going to an obstetrician. Indeed, the clinics of midwives are rare compared to those of obstetricians. According to Hanan Awada, a legal midwife I interviewed, there are nearly 30 clinics in Lebanon, a very small number in comparison to the number of legal midwives (Awada, 2019). Caline Sfeir, another legal midwife I interviewed, tells us about the experience, and the efforts and expenses incurred in order to reach independence and practice midwifery the way she wants to. She worked in hospitals more than once but felt limited and unable to practice what she learned. Nevertheless, she realizes that competing with obstetricians is a fantasy. The degree she holds does not give her a chance because of the trust society has invested in doctors. Caline continued her studies in France and specialized in obstetrical echography, novel to Lebanon. She considers herself fortunate to have been financially and socially able to travel to obtain an additional degree. Despite early sufferings, she was to persevere until people started coming to her clinic, and her subspecialty helped with that (Sfeir, 2019).

But what about midwives who possess neither the luxury of learning in French universities nor the time and social guarantees that enable them to do so? Why should women always strive to make more time and effort to succeed and why should they constantly prove their eligibility?

Nayla Doughane emphasizes this fact as she says:

The midwives working in clinics had a lot of responsibilities and expenses, which pushed them to prefer working in a hospital, but they lost their independence and became at the bottom of the pyramid, which is now headed by the doctor. Over time, this hierarchy has changed people's view of the midwife. (Doughane, 2019)

Thus, the hospital remains the only available, albeit not appropriate, option for midwives, most of whom work in hospitals as salaried employees. This salary does not exceed the sum of two thousand dollars, except in a few cases and after many years of work and accumulated experience, as reflected in my interviews. This salary covers a total of 3 to 4 working days in the hospital, within a 12-hour night or day shift. However, working in a hospital, regardless of the limited financial cost, restricts the functions of the midwife and makes her execute the obstetrician's instructions. The doctor has the authority to decide on the actions taken on the woman who is about to give birth, while the midwife is not entitled to participate in the decision. Caline Sfeir expressed her experience in the hospital as such:

I worked in the hospital more than once, but I felt very limited. I could not apply my convictions. A doctor always imposes his decision and has the sole right to decide on things. Working in a hospital limits the midwife and makes her act as a nurse. I know that I can receive childbirth and prescribe drugs. Sometimes I know that I am right but I must give in to the doctor's decisions. And after a certain period, I decided I could no longer take orders or work under such a system. (Sfeir, 2019) 
This exclusion takes place with the knowledge that the midwife accompanies the woman from the moment of arrival and performs all the tasks and care necessary for the woman to be fully ready for delivery until the doctor takes it from there, as Hanan Awada explained:

We do everything, all the tasks. We take the lady to the delivery room to let her see it and interact with it. We explain to her what we are going to do and what she is going to do, ask her about her medical history, talk to her, observe her to see if she needs an epidural injection, and stay with her. During this period, which may extend to more than 12 hours sometimes, the doctor comes once or twice at most for a maximum of 5 minutes or 10 minutes, and when the mother is ready for the delivery, he comes to execute it. (Awada, 2019)

Thus, the midwife does everything, except for obstetrics, her primary practice for thousands of years. She is left with the task of helping the doctor and caring for the woman giving birth, which is as important as medicine and plays a vital role in the recovery process. Yet, it is considered less valuable both financially and morally compared to "pure" medicine. This is organically linked to the gendered stereotyping of women, also responsible for determining the low value of their work. Women are responsible for their care labor, free of charge at home and in low wages in the workplace. "Women's" care labor is low-paid and has a low profile.

What we understand clearly is the dehumanization of women under patriarchy. She will first and foremost remain a woman, wherever she is. Thus, the way this system sees them as exploitable objects, targets of harassment, servile to men's decisions, and unpaid maids in houses will inevitably apply in hospitals' corridors. Originally based on the principle of excluding women, hospitals attempt in turn to keep women at the bottom of the hierarchy while ignoring their capabilities.

Caline Sfeir expresses the dynamics of male interaction, which is very similar to the dynamic of dealing with a father or husband, reproducing the man of the house as the man of the hospital, or the boss. "He has the highest authority," she mentioned while talking about the method she used to dissuade the doctor from opting for Caesarean sections, which she considers to be a hasty measure. Given the hierarchy, she could not express her opinion clearly, even if she was right. She said, smiling: "We have to find a way to convince him, talk to him quietly, and suggest a kind of circumvention rather than imposing our opinion. For example, we say to him, how about staying in your clinic until the end of the day, and then we see if the woman succeeded in giving birth in a natural way" (Sfeir, 2019). It is important to note that this is not to ridicule the doctor as an individual, who may or may not possess certain qualities, masculine or otherwise. Instead, we are attempting to paint a picture of a system that privileges a class in a dominant position over another, and doesn't hold it accountable when making mistakes, whether medical or moral, with patients, pregnant women, midwives, and nurses. There are many stories told by women who gave birth in hospitals and by nurses and midwives about the scorn of doctors and how they deal with women, be they patients, nurses, or midwives. The doctor is given a leeway to bully, demand, perform incorrect medical practices (I will address that in the last section), and harass. M.S., a midwife who refuses to give her full name, narrates that she was subjected to verbal harassment by an obstetrician in a hospital. In front of colleagues, the doctor had jokingly described her in a sexual position with him the night before as an explanation to her being tired the next day. As there was no way to understand his "joke," which was untrue, as anything other than unacceptable sexual harassment, she asked him to apologize, which 
he refused to do. She reported the incident to the administration that refused to process her complaint and tried to calm her down, saying that the doctor was joking and that it was okay for him to make such jokes because he always did. "That's just how he talks," they told her (Sfeir, 2019).

But does the doctor alone have the capacity to extend such authority? Does this power actually come from his skills and knowledge that exceed those of other health practitioners? Or does it get fed by and feeds on the structure of the patriarchal and capitalist system that oppresses and investigates women on the one hand, and makes health rights a difficult competitive commodity for the poor and those with limited income on the other? In the last section, I highlight different approaches and practices in maternal and reproductive health, as well as procedures and medical options for pregnant women, and the economic dimension of maternal and child health.

\section{Maternal Health is Controlled by the Obstetrician}

In this section, I compare the approach of traditional dayas and legal midwives with that of obstetricians working within the modern medical system, in order to highlight the differences in health outcomes between these two models. To do so, I consider several factors such as cost, quality of care, practice, and outcomes of maternal health in general. There is no doubt that the most prominent of these differences lies in the basic premises of the outlook on childbirth. Midwives understand pregnancy and childbirth as a natural act, that is to say, it happens organically, following a biological system equipped with its nature to complete the pregnancy and the delivery of the child. The woman does it according to the laws and dates of her body, thus recognizing the woman's body as conscious of its needs, in the sense that it can perform childbirth without additional medical procedure and the introduction of elements such as drugs and surgery, except in cases where complications or health problems are certain. The midwife considers that the required intervention should play an accompanying and parallel role for women in this delicate and intimate period, supporting them and their choices. The midwife sees a very powerful experience for women in pregnancy, and she looks at the subject in a comprehensive manner beyond the physical and organic interactions. She also sees that the health of the mother and the baby are subject to many factors interacting with each other to facilitate a natural path, ensuring safety, comfort, and trust. On the other hand, the doctor looks at childbirth as in need of treatment or at least a medical intervention. The task is limited exclusively to conducting tests and prescribing drugs, without considering the other care aspects needed by pregnant women especially, and everyone benefiting from health services in general. In fact, the concept of care is almost completely dropped, and the medical industry sometimes lacking humanity. A woman I interviewed told me about her traumatic childbirth experience, which led to a psychological crisis after giving birth. She says that the anesthetic didn't take effect immediately and she was still aware of her surroundings for a while. During delivery, she heard the doctor say that she was "fat like a cow, how will we turn her?" and similar terms (M, 2019). When not given the proper care, the pregnant woman becomes ill and her basic needs change, as care and follow-up are replaced by quick visits, a medical file, and a few medications. Nayla Doughane says in this context:

Our mission is not just to assist in childbirth; it's a task that starts from the very first moments of pregnancy. We accompany women in all stages of pregnancy, before and after. During these moments, there is trust building, exchange, and sharing of special and intimate issues. The 
relationship between women and midwives is a fundamental relationship in the life of women, which will empower women and give them the ability to choose the best options for their health. This intimate link was broken in the presence of the new equation that replaced this relationship with a doctor who may forget the details of the woman's case because she is a customer and he has to see the largest number of customers as soon as possible. Some women wait for the doctor to come back, not knowing that he won't, and they refuse to be examined by midwives until they lose hope. Women also lost their ability to set their reproductive choices and were subject to the doctor's instructions, which often dictate their reproductive decisions. The midwife, however, considers that the empowerment of women lies at the heart of ensuring they have access to better healthcare. And a good health ensures that they make conscious and informed decisions. (Doughane, 2019)

On the other hand, the healing witches and their granddaughters the midwives in this part of the world presented their work to the service of their societies, benefiting poor women who were unable to afford health care, and found in their practice a social role to play. When asked about her pay, daya Um Muhammad answered "A'outhoubillah! l've never asked for a single coin from anyone! It's my duty." She recalls the story of a family barely able to make ends meet. The father was insisting on paying her but she kept refusing and told him gently: "Son, buy a chicken with this money to nourish your wife" (Habib, 2011). Today, legal midwives are employed 12 hours a day for a fixed salary regardless of the number of women, births, and tasks, while the doctor sees a pregnant woman as a customer. More customers mean more profit and less time spent caring for each woman. In the hospital, a doctor is a paid contractor for every case that he attends to. The more cases he brings, the more authority he has in the hospital, and the less he is held accountable. As a result, the madness of making profit moves to the corridors of the hospital. The doctor becomes a quick visitor to the women, and sometimes he fails to reach the delivery room. The midwife does the job, but he still gets paid for her work. Sometimes, he also gets paid 'under the table' by the patient, in addition to what he receives from the hospital, according to Hanan Awada (2019). The practice of doctors is not limited to cutting their visit time and not providing care for financial gain, but it has established a pattern of medical practices that raise concerns such as the high rates of caesarean delivery, premature births, epidurals, and others. All these practices increase the doctor's financial profit. It is striking that this commodification of medical service takes place in partnership with the National Social Security Fund and insurance companies. Dr. Adnan Mroueh summarizes this process with remarkable precision:

In Lebanon, surveys since the 1990s show an upward trend in cesarean delivery... The highest percentage was in Beirut, where there are abundant numbers of centers and obstetricians, and the ease of hospitalization is available at the expense of the Ministry of Health. The percentage of cesarean delivery was low in North Lebanon as they still depended on home deliveries and a greater role for midwives. Access to cesarean deliveries increases with the availability of health insurance. This disparity in the adoption of cesarean delivery cannot be explained by scientific justification or physiological differences, but largely reflects excessive medical interventions... In Lebanon, excessive adoption of cesarean delivery may be associated with an abundance in the number of obstetricians... They seek to time the dates of delivery using drugs that stimulate uterine contractions, or they puncture the amniotic sac or perform a cesarean delivery. These interventions may increase the probability of obstruction or make a caesarean section a 
necessity. The timing of the date of delivery has increased from a low rate in the 1970s and 1980 s to $25 \%$ of births currently, for various reasons, the most important of which is the desire to avoid work at certain times, or to make more profit through a caesarean section. The hospital too has an interest in increasing the services it offers each family, to get a big return from insurance companies. (Mroueh, 2010)

The needs of mothers are physically and psychologically vulnerable due to blind trust in doctors' approaches to maternal health decisions, and their application on women's bodies that excludes the women themselves. The imposition of inappropriate interventions increases profits and minimizes time to rise the number of patients. According to the little we have reported, obstetricians in Lebanon are not only abandoning the approach of conception by birth, but also violating the recommendations of the World Health Organization (WHO) on ensuring the quality of health services related to maternal health: safety, i.e., not to harm the patients by the treatments that are supposed to cure them; the centrality of women, i.e., to provide respectful and responsive care to the patient's options, needs, and values; efficiency, i.e., avoidance of the potential waste of equipment, materials, ideas, and energy; and the provision of services based on scientific knowledge to all who need it.

\section{Conclusion}

We can draw from the above that patriarchy and capitalism are twins that feed and complement each other. Together, they create a miserable world for its inhabitants who stripped of their most basic rights to increase profit. Patriarchy works to suppress and punish women so that they become more vulnerable to exploitation, at home where they work free of charge, and in the labor market, which continues to pay low wages for hard work. The medical sector is not separated from the whole system as it relies on patriarchal rhetoric and laws that once again dismiss women as ignorant and incompetent. It diminishes their values and terrorizes them by violating their senses and bodies through verbal and physical harassment, and abuse. These tools limit their access to their rights and their enjoyment of professional and personal progress and independence. Naturally, the Patriarchy Achievement Award goes to capitalism that doubled its worth from not being compatible with women's methods and approaches in the health sector. Women work in hospitals for hours on end, and doctors use inventions and medical interventions that increase the value of the bill. The complicity in this organized looting is carried out with the blessing of the Lebanese government, whose social security fund is liable for the cost of every birth performed by a hospital doctor. The legal midwives are employed in a uniform salary regardless of the number of births. Today they are members of a syndicate and hired to perform normal deliveries.

Modern medicine has excluded midwives under the claim that their practice is inefficient and increases maternal and neonatal mortality, as well as the spread of infections and other health problems. However, modern medicine appears to be more dangerous to maternal health today. The reduction of maternal mortality has become a Millennium Development Goal, and medical procedures are becoming an increasing threat to maternal health, both in terms of increasing caesarean section, pre-delivery of births, women's access to drugs, and other procedures. More importantly, this modern medical system excludes the poorest and most marginalized from having access to health services. The most prominent aspect of cooperation between patriarchy and capitalism is the establishment of a consumer culture among 
mothers, whose choices are mainly based on the elitist appearance of birth, the fashion of choosing attractive birth dates or famous doctors, and the trend towards caesarean sections to avoid labor pains or avoid "distorting" their reproductive organs during a natural delivery.

What is required today is to expose this system, and to allocate more resources and support to midwives in all available forms. This paper is the result of voluntary work with limited resources. Many facts remain obscured because of patriarchy. There are voices waiting to tell their story, both in terms of the dedication of dayas formerly and legal midwives today, or by women who are uncomfortable with their relations with obstetricians. This paper has tried to answer many questions, but it ended with bigger and deeper ones that require effort, resources, and commitment to bring justice to our grandmothers, ancestors, and Mother Nature. 
Awada, H. (2019, April 24). Midwife. (H. Abbani, Interviewer)

Barbara Ehrenreich, D. E. (1973). Witches, Midwives, and Nurses: A History of Women Healers (Second Edition ed.). The Feminist Press.

Doughane, N. (2019, February 26). Midwife. (H. Abbani, Interviewer)

M, N. (2019, January). Mother. (H. Abbani, Interviewer)

Osman, S. (2019, April 10). (H. Abbani, Interviewer)

S, M. (2019, March 22). Midwife. (H. Abbani, Interviewer)

Sfeir, C. (2019, April 04). Midwife. (H. Abbani, Interviewer)

WHO. (2018). World Health Statistics: Monitoring Health for the SDG's.

World Health Organization, W. (2018). World Health statistics: Monitoring Health for SDGs.

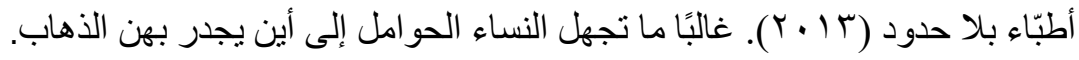

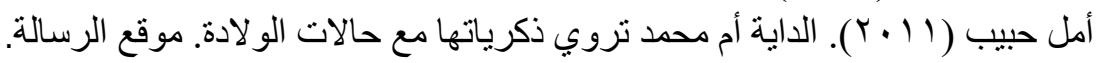

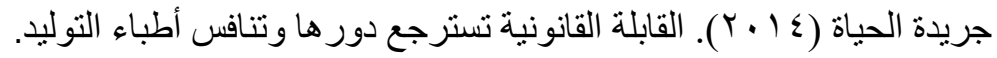

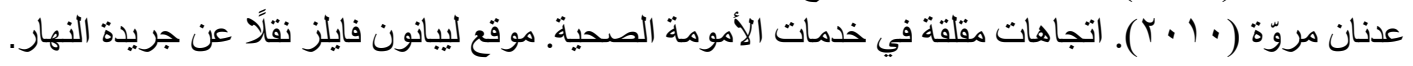

$$
\begin{aligned}
& \text { نقابة الأطباء (9V9 ( ) ). قانون تنظيم ممارسة مهنة الطب في لبنان. لبنان. }
\end{aligned}
$$

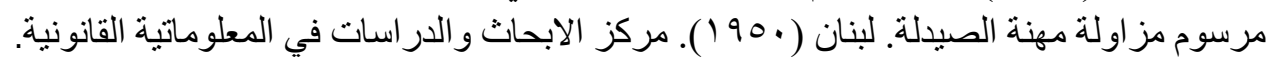

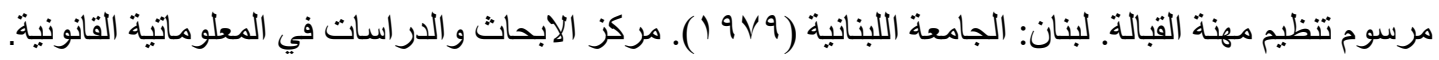

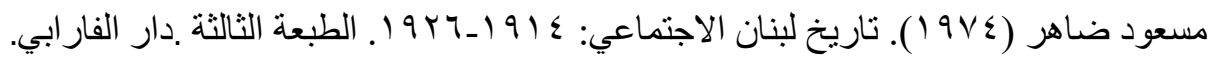

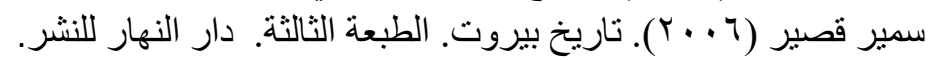

